\title{
A Comparative Study of English and Chinese Film Title Translation- - from the Perspective of "Four Values"
}

\author{
Jialiang Chen ${ }^{1}$ \\ ${ }^{1}$ School of English for International Business, Guangdong University of Foreign Studies, Guangzhou, China \\ Correspondence: Jialiang Chen, School of English for International Business, Guangdong University of Foreign \\ Studies, No.2 Baiyundadaobei, Guangzhou 510420, P.R.China. Tel: 0086-150-8977-5557. E-mail: 20190310011 \\ @gdufs.edu.cn
}

Received: December 11, 2020; Accepted: December 22, 2020; Published: December 23, 2020

\begin{abstract}
With the deepening of cultural exchanges between China and western countries, interaction and dissemination of film works have become a common trend. A film title is the "eye" of a film; therefore, concerning the differences between English and Chinese languages, film title translation should not only convey necessary information about the films to the corresponding audience in the target language, but also arouse the interest of the audience to achieve a satisfactory box office. Based on the theories of functional equivalence and communicative translation, and especially "four values" serving as the evaluation standard of film title translation, the thesis makes a comparative analysis of English and Chinese in film title translation and evaluates it with evidence from the successful experience of C-E (Chinese to English) and E-C (English to Chinese) translation from 2016 to 2019 in order to provide references for $\mathrm{C}-\mathrm{E}$ film title translation under three translating techniques, thus promoting the value of title translation and the entrance of Chinese films to international markets.
\end{abstract}

Keywords: comparative study, film title translation, "four values", translating techniques

\section{Introduction}

There has been an increasing trend in international communication in films nowadays. With the implementation of China's reform and opening-up policy, a large number of foreign films have poured into the Chinese market (Wang, 2019). In order to meet the growing demand of the Chinese audience for films, English films have been translated, and film title translation is of great significance to a large extent. The past decades has also witnessed significant progress in the film industry of China, reflecting the increasingly open and varied attitude towards the production and promotion of Chinese films. At the same time, Chinese film producers are doing what they can to promote Chinese films in foreign markets, among which, the English-speaking countries occupy the main proportion. However, due to great differences in languages and cultures between China and English-speaking countries, the promotion of Chinese films in English-speaking countries will be achieved with the differences properly reconciled. In this regard, film title translation is an initial and fundamental step of film translation.

The success of some previous English films in the Chinese market has offered practical instances and experience for the current Chinese films to take for reference in order to play their role in the foreign markets. Accordingly, a great many Chinese films entering the English cinemas every year display a relatively comprehensive picture of the C-E film title translation respectively, which provides people with numerous references. With the introduction of a large number of foreign language films, as well as an increasing number of Chinese films going abroad, the issue of film title translation has been put on the agenda. As early as 2000, Qian (2000) wrote an article calling on the translation circle to attach great importance to film title translation. The film title plays a direct role in guiding and promoting the film. Therefore, the quality of film title translation has a direct impact on the artistic display and commercial attraction of the film.

Combining functional equivalence, communicative translation theory with the characteristics of film titles, He (2001) proposes the standard of film title translation, the concept of "four values", serving as the main principle for evaluations on the effect of film title translation, namely informational value, cultural value, aesthetic value, and commercial value. The present study intends to offer references concerning the translation of Chinese films in English-speaking countries on the basis of the "four values". Since research rarely touches on a comparative perspective, this study seeks to fill this gap with a comparison of C-E and E-C film title translation.

\section{Theoretical Basis and Framework}




\subsection{Theoretical Basis}

\subsubsection{Functional Equivalence Theory}

According to Eugene Nida (1974), dynamic equivalence, the term as he originally coined, which was later preferred as functional equivalence, is the quality of a translation in which the message of the original text has been so transported into the receptor language that the response of the receptor is essentially similar to that of the original receptors. In his essay, Principles of Correspondence, Nida states that "no two languages are identical, either in the meanings given to corresponding symbols or in how symbols are arranged in phrases and sentences; it stands to reason that there can be no absolute correspondence between languages" (2004: 153-167). Hence, there can be no fully exact translation. Functional equivalence not only refers to the equivalence between the function of the source text in the source culture and the function of the target text in the target culture, but can also be regarded as an attribute of the text, which shows that functional equivalence can be related to how people interact in culture. Dynamic equivalence (functional equivalence) includes four aspects: lexical equivalence, syntactic equivalence, textual equivalence, and stylistic equivalence, among which, Nida believes, "meaning" is the most important, followed by form (Guo, 2000). When it comes to the translation between English and Chinese, for example, English speakers usually use nouns as they are static, while Chinese speakers prefer verbs to describe dynamic situations (Lian, 2010).

Therefore, the translator converts the deep structure of the source language into the surface structure of the target language; that is, the corresponding words in the target language can directly explain the connotation of the original text so as to make the target readers more receptive to the translation. According to Nida's translation theory, the treatment of cultural differences is closely related to the reproduction of source language in the target language from semantics to style. Only when the translation reproduces the style and spirit of the source language from the linguistic form to the cultural connotation can the translation be regarded as an excellent piece of work (Guo, 2000). In the case of film title translation, its purpose is obviously more imperative to meet the potential interest of the audience. Regarding Nida's (2004) theory, a good film title translation should be: (1) highly intelligible, because it conveys a clear message to the potential audience; (2) an attractive form, wording, or any other semantic aspect that may appeal to the potential audience.

\subsubsection{Communicative Translation Principle}

Peter Newmark (1981) referred to translation as either semantic (word-for-word) or communicative (sense-forsense). He stated that semantic translation is more literal and faithful to the source text, focusing on the source language, while communicative translation is free and idiomatic, from the perspective of the target language. In other words, the goal of a communicative translation is to produce on the readers an effect close to that produced upon the readers of the original (Newmark, 1991).

Communicative translation (or communicative approach) refers to any translation method or approach that regards translation as a communicative process occurring in a social context (Hatim \& Ian, 1990). Although all translation approaches regard translation as communication to some extent, the communicative translation mentioned here is completely oriented to the target language reader or receiver. With the aim of communicating certain information, film title translation accordingly involves the realization of the transmission of information, the stimulation of the potential desire to watch (Cao, 2007), thus arousing the audience's aesthetic resonance.

Newmark (1991) also proposes that "there is no one communicative or one semantic method of translating a textthese are in fact widely overlapping bands of methods" (p. 10). In terms of film title translation, the question of whether the translation is semantic or communicative involves the extent to which these two methods are used, rather than merely translate the text using semantic or communicative methods. Although the translation method of a film title is more communicative, the semantic method can better retain the taste of the original title in some cases, thus making the title more attractive in an aesthetic way.

\subsection{The "Four Values" of Film Title Translation}

The study of film title translation, which dates back to the late 1980s, has so far mainly presented three trends. It was believed in the 1990s that based on the application of traditional Chinese translation theory, translators regarded "faithfulness" as the priority, and emphasized that film title translation must be faithful to the original title (Bao, 2001). After 2000, some scholars began to use the theory of manipulation school to explain the phenomenon of inconsistencies in film titles translated from mainland China, Hong Kong, and Taiwan. However, another group of scholars believed that film title translation belongs to advertising translation, and commercial factors should also be considered (Yue, 2000; Li, 2002). 
The realization of the "four values" of film title translation is complementary and indispensable. He (2001) argued that the realization of "functional equivalence" in film title translation is closely related to "four values". In order to achieve the equivalence of titles regarding informational, cultural, aesthetic, and commercial functions, it is necessary to make good and full use of the advantages of the target language and "re-create" (Guo, 2000) it, translating the original title with the language form that people are willing to see and hear in the target culture with the "closest natural equivalence" (Nida, 2004) and achieve the communicative effect. Previous studies focus more on one-way translation to evaluate the effect. Little attention has been paid to a comparative study of translation, therefore giving the present study a new insight in researching film title translation.

\subsubsection{Informational Value}

About information theory, "information processing consists of an input-output function that maps any input sequence from $\chi$ into an output sequence from $\Upsilon$. The mapping may be probabilistic or deterministic. It may have memory or be memoryless" (Stephen \& Kim, 2003). When it comes to film title translation, Qin (2015) focuses on the realization of informational value with three points as follows. First, under the principle of informational value, film title translation should be based on the equivalence of information, which encodes with the functional equivalence as well. Second, in terms of informational value transmission, sometimes film title translation may, however, make the audience have some misunderstanding of the film because they tend to interpret the film titles too literally. Third, while the film title is limited by its length, the content of the refraction is huge. It is necessary to use a limited number of words to guide the audience without bias to the whole film to establish an impression of understanding, which makes the translation in a clever and proper way considered to be of great significance. The equivalence and accurate transmission of information require translators to have a certain perception and grasp of the film itself. At the same time, in addition to fully mastering the content of the film, the translator should also study the pragmatic conventions of the target language so as to achieve the aim of high-quality film title translation.

\subsubsection{Cultural Value}

Cultural translation solves some issues linked to culture, such as dialects, food and architecture. The main issue that cultural translation must solve lies in translating a text as showing cultural differences in respecting the source culture (Cartford, 1965). Catford illustrated the theory of cultural untranslatability in his book Linguistic Theory of Translation: Cultural untranslatability arises when a situational feature, functionally relevant to the source language text, is completely absent from the culture of which the theory of translation is a part (Cartford, 1965), such as the names of some institutions, clothes, foods and abstract concepts, amongst others, which frequently appear in film titles.

Zheng (2014) mentioned four main aspects regarding the differences between Chinese and English cultures from a cross-cultural perspective: values, ways of thinking, aesthetic ideas, social customs, religious beliefs, and historical allusions. For example, British and Americans have always believed in individualism and power, that all men are created equal, while Chinese people value the whole community, highly praise ethics and pay attention to seniority and inferiority. Also, Chinese films like to use a holistic and abstract way to translate film titles, and tend to add some verb elements. However, many people do not have enough knowledge of different cultures presented in film titles. Therefore, special attention should be paid to the film titles related to cultural elements before the translation is done.

As a social product of cultural phenomena and ideological trends, film titles are bound to have typical national characteristics together with cultural values. Film title translation is not only to transform the title from the source language to the target language, but also to bridge the gap of cross-cultural barriers and create cultural value (Bao, 2001) in the film title. In film title translation, a good translation must cover relative cultural connotation and necessary cultural adaptation (Cao, 2007). Deciphering and rearranging the cultural connotations peculiar to one culture but strange to another will make the translation understandable to the audience in the foreign language market. Thus, if the translation can both achieve the cultural intelligibility of the target culture and integrate the linguistic characteristics of the target culture, then its cultural value can maximize the publicity effect of the film title.

\subsubsection{Aesthetic Value}

Aesthetics is a branch of philosophy that deals with the nature of art, beauty, and taste and with the creation or appreciation of beauty (Classe, 2000). In its more technical epistemological perspective, it is defined as the study of subjective and sensori-emotional values, or sometimes judgments of sentiment and taste (Zangwill, 2008).

Reception aesthetics holds that the vitality of a work lies in the participation of readers, which means that a film without an audience will lose its value of existence (Wan, 2018). The film title is the "eye" of the film that enables 
the audience to guess the content of the film through the name; in other words, the audience may decide to watch the film or not with a glance at the film title. Therefore, it can be understood that film title translation can influence or even determine the box office of a film. Film title translation should not only faithfully reflect the content of the film, but also make it acceptable to the audience. Wan (2018) also states that according to the viewpoint of reception aesthetics, the translator should consider not only the original intention or intention of the director or creator, but also the content (text) and the taste of the audience. The fundamental task of realizing the aesthetic value is to reproduce the beauty of the original film title in the target language and convey it to the audience. In the realization of aesthetic value, attention should be paid to the refinement of language and the use of rhetorical devices in translation. The choice of words and the organization of the form will set the tone for the style of the title. Translators should try their best to choose the words that can best present beauty to the audience in the target language from the sound, form, and meaning of the title. A good title can create an artistic atmosphere and enhance the film's aesthetic value. The representation of rhetorical devices can be employed to realize the aesthetic value of English film titles. Translators may reproduce or creatively refer to rhetorical devices in translation to bring artistic appeal to the Chinese audience.

\subsubsection{Commercial Value}

The film is not only the art of modern science and technology but also a product of science and technology and art perfect combination (Wang, 2008). It is based on the foundation of modern material civilization, the industrial and post-industrial society to generate and cultural environment of survival, huge funds for the operation of the basic premise, etc, which is undoubtedly a typical commercial symbol. In today's society with the information explosion where advertisements are flooding in and forms of entertainment are emerging endlessly, the audience will screen out most of the information due to their perceptual choices, thus choosing a few pleasant recreational activities. In this case, how to allow the film title to make a deep impression on the audience is of great significance. If the audience can have various needs for the film after watching the film title, the characteristics of the film will immediately emerge in their mind. Thus, a successful film title is a key link to attract the audience into the cinema. On the other hand, if the film title cannot attract consumers, it will lose a large audience, so that they will choose other forms of entertainment for profit (He, 2001). If the film's communicative purpose cannot be achieved, its commercial value cannot be achieved accordingly. Therefore, film title translation is to guide the needs of the audience under the guidance of a certain purpose, so that the exchange of film as spiritual consumer goods can be smoothly realized.

\section{Analysis: A Comparative Study of C-E and E-C Film Title Translation}

\subsection{Informational Value}

The translation of cultural information is one of the most basic purposes of translation. While film titles only contain a few words, the connotation is very rich and profound, because a few words can stand for the theme to a certain extent. As the essence of the film can be reflected simply from the title, the audience can know the theme of the film, characters, content, and the general plot of the story. However, one mistake that needs to be avoided is that translation is not only the transcoding between two language symbols (that is, the conversion of one language into another language), but also the communication and transmission of information between two languages and cultures (Fan, 2018). Most of the original film titles are aimed at the audience in English, which is influenced by its low-context culture. However, Chinese film titles are presented in a relatively high context and cultural environment, in which hints are sometimes expected to enrich the titles with flavor. The fact that these two cultures have a low- or high-context culture directly influences the difficulty of title translation, especially in retaining useful information in the original text.

When English films are translated into Chinese, some supplement information is added to attract the audience. Alpha (2018) is a film that talks about the relationship between the protagonist and the wolf. Alpha is the name of the wolf, making simply translating it into Chinese under transliteration sound unorthodox. As a result, the translator employs the method of amplification, making additions “狼伴归途” (returning accompanied by the wolf) of the main plot of the film as 阿尔法: 狼伴归途. Another example is A Dog's Purpose (2017), which tells the story of a dog that has been reborn many times to look for different missions in the cycle of life and finally returns to his original owner. If the translator directly used “一条狗的使命” under literal translation, it might make the Chinese feel confused about the content of the film. As a consequence, the translation is done with amplification as well. 一条狗的使命: 只为遇见你 is a better version where “只为遇见你” (only to meet you) reveals the purpose of the dog, echoing with the theme of the film properly. It can also be found in a very famous film Zootopia (2016), which provides a general picture of the interesting stories that happen at the zoo. The translation version 
flexibly rearranges the title into 疯狂动物城 (a crazy city of animals), enabling the Chinese audience to better perceive and comprehend the film at the first sight of the title.

For Chinese films, informational value is displayed during the translating process due to the shift from high-context to low-context culture. 少年的你 (2019) has won a great box office as it manages to raise the childhood of many Chinese people concerning campus bullying. Considering different cultural backgrounds between China and English-speaking countries, translation versions such as "when you were young" or "your childhood" may appear confusing at the first time. Therefore, the translator switches the title into Better Days, which is in line with the values implied in the film, describing the typical campus life experience of Chinese students. Another influential film in 2019 is 哪吒之魔童降世 (2019), which ranks first in douban, one of the public evaluation platforms in China. Since “哪吒” is a well-known child image in traditional Chinese culture, it may be easier for Chinese people to have a better perception and prediction of the name. However, when the film is targeted at westerners, relevant interpretation needs to be kept and added to enable the western audience to comprehend such an unfamiliar image, which makes the translation into Nezha: Birth of the Demon Child.

In order to better realize the informational value of film titles, translators are advised to summarize the theme or the content of the film, followed by making some additions, adjustments, and reductions to the original title. If possible, they can try providing some background information or genre of the film in order to make it possible for the target audience to gain a general understanding of the film.

\subsection{Cultural Value}

Film title translation in China has gone through different stages. In the early stage of cultural exchange, due to the unfamiliarity between cultures and the audience's actual ability to accept, domestication was once preferred. Wu (1995) commented that the domestication of film title translation is to turn the target language into the target language, to help the audience bypass the obstacles to understand the film content and to translate in line with the aesthetic standards and cultural intentions of the people of the target language countries.

Cultural elements are usually taken into account for English films in the Chinese market. Avengers: Infinity War (2018) is translated into 复仇者联盟 3：无限战争, which adopted the amplification with “联盟” (union or ally). In cross-cultural communication, Chinese culture is collective, while western cultures prefer individualization, which makes the translator choose to add "union" in the translation version for the series of films. Moreover, Fantastic Beasts: The Crimes of Grindelwald (2018) also employs amplification with “在哪里” (where is...), which makes the title 神奇动物去哪里 2: 格林德沃之罪. Besides, Mission: Impossible - Fallout (2018) is translated into 碟中谍 6 : 全面瓦解, which roughly tells a story that the protagonist, on a spy mission, in addition to facing terrorists, has to face the ghosts hidden in the government departments. The liberal translating technique is applied here, for “中” (in or within) is frequently used in Chinese culture to describe a complicated situation, such as “局中局” (a game in a game), “梦中梦” (a dream within a dream), and “画中画” (a picture within a picture), etc.

When it comes to Chinese films in English-speaking markets, cultural (historical) knowledge plays a role since some of them are unknown to the foreign audience. 这就是命 (2017) talks about the protagonist who is accidentally involved in a big case encountered a series of troubles. The English version Kill Me Please vividly describes the terrible situation the protagonist is faced with. On the contrary, if via literal translation, "This Is Life" or "This Is Fate" seems to be awkward since "life" and "fate" are often applicable to significant events in English. 明月几时有 (2017), which in Chinese refers to a famous poem in the Song Dynasty, but it appears to be unfamiliar to the foreign audience. Therefore, the translator chooses to re-create the title based on the English culture and translates it into Our Time Will Come from the content of the film. Another example is 火锅英雄 (2016), which is translated into Chongqing Hot Pot. "Chongqing" is an amplification that adds to the background information of the film since Chinese people are familiar with this image but foreigners may fail to.

To better realize the cultural value of film titles, translators are advised to introduce foreign elements into film title translation in order to make it accessible to the target audience. If possible, they can try transplanting target cultural elements to create a sense of intimacy between the original title and the translating version.

\subsection{Aesthetic Value}

A film title is often the product of the careful conception of the scriptwriter, not only concentrating on the content, but also having its own unique information function and aesthetic function. Beautiful, smooth, vivid film titles can guide the audience to feel the charm of art, stimulate the aesthetic pleasure of the audience. Thus, it has an invisible influence on consumers, which means the abundance in artistic imagination of the title will play a promotional role that cannot be underestimated ( $\mathrm{Lu}, 2015)$. It is familiar to us that Chinese translation theorist Yan Fu proposed 
the three principles in translation: faithfulness, expressiveness, and elegance (Shen, 1998). Film title translation is therefore expected to reach such standards, especially elegance in order to reach the aesthetic value.

English and Chinese have different preferences in the choice of words to achieve rhetorical effects respectively. Despicable Me 3 (2017) is the third story in the Despicable Me film series and the sequel to Despicable Me 2 (2013), translated into 神偷奶爸. The film tells the story of Gruden, after being expelled because of a failure in action, who restarts their bad guy career for justice. Since it is a comedy film, it is inappropriate to translate “despicable" directly into “卑鄙”. Rather, given the desired effect, it is better to translate the title into a positive expression in Chinese. The translator chooses to use “神偷” (expert thief) to replace the negative meaning of “despicable", which, to a certain degree, shows the implication of the plot of the film. Moreover, with “奶爸” (new dad) as an amplification that is a popular expression in China, it has fully reached its aesthetic value.

The same goes to the promotion of Chinese films into English-speaking markets. The greatest difference between the original title 三少爷的剑 (2016) and the English version Sword Master is the description of the subject, respectively the weapon and the role. In Chinese, “三少爷” has its own sense concerning hierarchy, but it is quite unfamiliar to the foreign audience. In this regard, the translator keeps the weapon and uses an idiomatic expression “master", which is common and preferable by the English audience, to refer to the leading role. In addition, 谁的 青春不迷茫 (2016) has its title version as Yesterday Once More, which has referred to the name of a famous English song, therefore fitting in with the aestheticism of the target audience.

我不是药神 (2018), translated into Dying to Survive, is another typical example of the full realization of aesthetic value. It tells a story that, in the condition of the high price of incurable drugs, the adventurous group goes abroad for importing drugs to treat patients illegally in order to survive. The title can be analyzed with three aspects. First of all, "dying" employs a pun. For one thing, "dying" is similar to "eager" but with the strongest sense among other synonyms, echoing with the plot that the patients are desperate for the medicine to survive. For another, "dying" also reflects the condition that the patients are exposed to and the situation that they are faced with. In addition, "dying" and "survive" are contradictory so that they form a strong contrast, which is an oxymoron in English. At last, compared with "live", the use of "survive" is much better, for it displays an urgent situation and a very low probability of living. With the employment of rhetorical devices and the proper choice of words, the title Dying to Survive has fully reached its aesthetic value and left a strong impression.

To better realize the aesthetic value of film titles, translators are advised to take advantage of the features of the target language, adapting to fixed forms of expressions in that language to arouse different emotions of the audience. If possible, they can try to employ rhetorical devices in order to achieve beauty in the form.

\subsection{Commercial Value}

Translators should take into account the cultural and commercial art that is connoted to the film when the translation is carried out. In order to realize the commercial value, the translator should have a thorough understanding of the cultural and aesthetic characteristics of the film from the very beginning and create the title from the angle of the target audience to raise their psychological identity, stimulate aesthetic pleasure and arouse the desire to watch (Wang, 2008). Film promotion itself is a commercial operation, and a good title means good marketing.

Disney films are a representative example as they have long been known for creating princess images to attract different audiences around the world (Chen, 2020). The film Moana released in 2016 is one of the series of Disney films, which came out in the Chinese cinemas titled 海洋奇缘. When the title is the name of a heroine, the translator prefers to use her related characteristics added by two Chinese characters “奇缘” (Yang, 2018). Names such as Moana are unfamiliar to the Chinese audience due to lack of cultural background knowledge, therefore requiring the translator to re-create the name of the film with reference to the contents of the film. In the film, the ocean is the basic context and element, so it has been chosen to form the new title with “海洋” (ocean). This kind of translating methods can date back to the film Pocahonta (1995), which was translated into 风中奇缘. Therefore, the translators of the following films decided to make the expression “奇缘” (fancy destiny) an exclusive feature of this kind of princess films, such as Enchanted for 魔法奇缘, Tangled for 魔法奇缘 and Frozen for 冰雪奇缘. Yang (2018) argued that when the Chinese audience see the words “奇缘”, they naturally regard the film as one of the series of Disney princess films. Meanwhile, they can tell from the modifiers what may happen in the story, leaving room for imagination and expectation. The same also goes for the expression “总动员” (general mobilization), such as the film Finding Dory (2016), translated into 海底总动员. Therefore, the reuse of “奇缘” and “总动员” can bring better marketing benefits, reflecting the commercial value of film title translation.

Translating Chinese films into English and promoting them in the English-speaking markets has a shorter history compared with those introduced to China. An example of how Chinese films manage to add commercial factors 
to the movies is the translation of 西虹市首富 (2018). The film tells the story of an amateur goalkeeper who was expelled from the team, unexpectedly inherited a large fortune, resulting in a series of interesting events. The film was translated into Hello Mr. Billionaire, referring to the famous British novel The Million Pound Note, which talks about how to deal with an unexpected fortune as well. This kind of translating method can arouse the interest of the audience in English-speaking countries based on their previous understanding of the novel.

To better realize the commercial value of film titles, translators are advised to use enticing words to arouse different emotions of the audience. If possible, they can try relating the title to a specific subject that plays an influential part among the audience to appeal to the target audience.

\section{Discussions: The Application of "Four Values" with Translating Techniques}

Film titles are both commercial and artistic. From the commercial point of view, in order to achieve the expected value, the translated title will highlight the film content, reveal the theme of the film, and accordingly better convey the film information to the audience. The box office is the ultimate goal of the initiator (producer) of the translation activity (Ji, 2008), which determines that the translation should fully consider the expected horizon of the target audience and effectively play the expected function of the title. From the artistic perspective, the film title is a beautiful packaging, and the purpose of the translation is to guide the audience to feel the charm of art, so the translation should take into account the language and cultural accomplishment as well as aesthetic taste.

Given the analysis of "four values", relevant translating techniques will be discussed in this section with successful examples of Chinese film titles into English versions. Altogether, a theoretical framework is presented for reference in Figure 1.

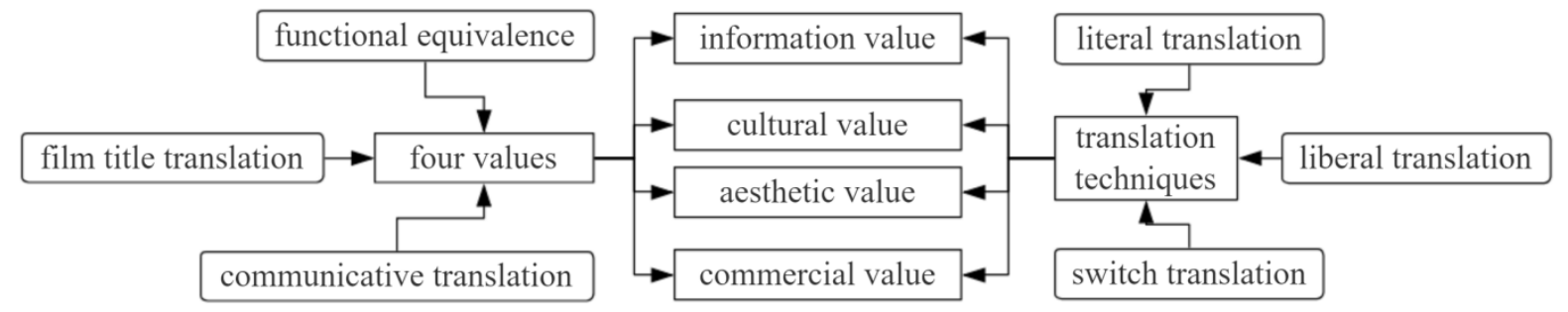

Figure 1. Film Title Translation Based on "Four Values" \& Translating Techniques

\subsection{Literal Translation}

In translation study, "literal translation" denotes technical translation of scientific, technical, technological, or legal texts (Olive, 2000). Liu (1991) defines the literal translation approach in this way: "in the process of translation, literal translation treats sentences as basic units and at the same time takes the whole passage into consideration; a translator who attaches great importance to literal translation does his or her best to reproduce the ideas and writing style of the original work, retaining in the version as many rhetorical devices and sentence structures of the original as possible." When the literal translation is applied, the film title is translated in a conservative way, so the cultural style of the original text is conserved accordingly so that the audience can have direct access to the cultural characteristics of the original text. This translating technique forms the main types of film title translation.

Here are some successful examples of translating the title under literal translation. 美人鱼 (2016) is translated into Mermaid, and 涺公河行动 (2016) into Operation Mekong. Besides, 芳华 (2017), which literary means “youth" in Chinese, is naturally translated into Youth. More examples such as 巨齿藫 (2018) into The Meg and 战 狼 2 (2018) into Wolf Warriors 2 are carried out under literal translation since their senses between Chinese and English are literally linked.

As for Chinese film titles without complicated cultural implications, literal translation is a proper means of translation, because it can directly reveal the equivalence of the original title and the translating version so that the audience will be less likely to feel confused when they see the title. Thus, based on the equivalence, the informational value of the original title can be straightforwardly communicated and the cultural connotation can be clarified with the aesthetic value of the corresponding expressions. 


\subsection{Liberal Translation}

According to Liu (1991:56), "liberal translation is supplementary to literal translation." Liberal translation, often called free translation, means abandoning the original form of expression and trying seeking for a proper way to express what the original text is intended to convey. It is used to express the idea of the original title instead of representing the sentence structure or rhetorical devices employed. The purpose of the liberal translation is to realize functional equivalence, leaving a similar impression on the target audience compared with the original targets. In film title translation, a liberal translation is often employed when literal translation fails to reach the intended effect due to cultural and linguistic differences.

记忆大师 (2017) is translated into Battle of Memories, which retains “记忆” (memory), but turns the “大师” (master) into another word "battle". Based on the content of the film concerning the conflict of memories, the translator tries to present the film title in another way. The same goes for 从你的全世界路过 (2016) into I Belong to You. Literally translated, the title would be "I passed by your whole world", which looks awkward in a way from an English angle. As a result, the translator tries keeping the significant elements "I", "you", and the relationship between the two, re-creating the structure and using an idiomatic phrase "belong to" to replace "pass by". The translation manages to reach the cultural value at first glance and turns out to fully realize the aesthetic value of the title. Also, 傲娇与偏见 (2016), focusing on the personality of the protagonists, is translated into $M r$. Pride vs Miss. Prejudice, which vividly represents the characteristics of the film.

When a liberal translation is applied, film title translation allows more room for the fulfillment of the original information and cultural characteristics between English and Chinese. Meanwhile, given the equivalence of form and structure, chances are that more aesthetic and commercial value can be brought about to the film accordingly, which enables the target audience to form an impressive expectation of the film.

\subsection{Switch Translation}

Generally speaking, in view of translation, priority is usually given to faithfulness. But when it comes to film title translation, it will be another situation, for film titles have distinctive features from others in its functions concerning both communication and profit (Wang, 2008). If neither literal nor liberal translating methods manage to take on a satisfactory result, the translator may need to come up with a new title based on the content of the film instead of making adjustments to the original title. Under switch translation, the translator re-creates the title irrelevant to the original version but related to the film itself.

一出好戏 (2018) is a comedy film that talks about the adventures happening on an island. If the translator translates it into "An Interesting Story" under literal translation or changes something else under liberal translation, it will lose its original sense when facing the target audience. Therefore, the translator re-creates the title completely based on the film content, using the scenario as the new title, that is, The Island, which creates certain suspense and arouses the interest of the audience. Another example is 七月与安生 (2016), telling a story about two sisters from the age of 13 who began to know each other, love each other, and grow together. As the original title is formed of the names of the two girls, it makes no difference to the target audience, which can be further evaluated based on cross-cultural theories of high- and low-context cultures. Thus, based on the film content, the translator takes into account the relationship between the two girls and replaces it with SoulMate, greatly echoing the theme of the film.

Differing from other translating methods bringing faithfulness to the original title, switch translation aims to recreate informational value instead of slightly adjusting the source information. Switch translation requires considerable efforts of the translator because it helps to avoid the cultural connotation that may arise and directly suit the taste of the target audience, therefore promoting the aesthetic and commercial value.

\subsection{Summary}

To establish a comparatively critical understanding of the film title translation, the author has collected 100 Chinese films and English films respectively from 2016 to 2019 and analyzed the methods employed in their translation as in Table 1. After calculating the number and percentage in Table 1, Table 2 is presented below.

Table 1. Frequency of Translating Techniques

\begin{tabular}{|c|c|c|c|c|c|c|}
\hline \multirow{2}{*}{\multicolumn{2}{|c|}{$\begin{array}{c}\text { Literal } \\
\text { Translation }\end{array}$}} & \multicolumn{3}{|c|}{ Liberal Translation } & \multirow{2}{*}{$\begin{array}{c}\text { Switch } \\
\text { Translation }\end{array}$} & \multirow{2}{*}{ In Total } \\
\hline & & Amplification & Omission & Adjustment & & \\
\hline $\mathrm{E}-\mathrm{C}$ & 29 & 31 & 8 & 2 & 39 & 109 \\
\hline
\end{tabular}




$\begin{array}{lllllll}\text { C-E } & 38 & 6 & 16 & 8 & 39 & 107\end{array}$

Table 2. Frequency \& Percentage of Translating Techniques

\begin{tabular}{ccccccc}
\hline & \multicolumn{2}{c}{ Literal Translation } & \multicolumn{2}{c}{ Liberal Translation } & \multicolumn{2}{c}{ Switch Translation } \\
\cline { 2 - 7 } & Frequency & Percentage & Frequency & Percentage & Frequency & Percentage \\
\hline E-C & 29 & $26.60 \%$ & 41 & $37.70 \%$ & 39 & $35.70 \%$ \\
C-E & 38 & $35.50 \%$ & 30 & $28.10 \%$ & 39 & $36.40 \%$ \\
\hline
\end{tabular}

The proportion of the literal translation of film titles is relatively low, with the proportion of literal translation of English film titles $26.6 \%$, and the proportion of translation of Chinese film titles $35.5 \%$. This result confirms that the principle of faithfulness sometimes may give way to the evaluation of four values.

Meanwhile, Chinese film title translation presents the trend of two levels; that is, a literal translation and switch translation are regarded as high relative translating methods, with the proportion of $35.5 \%$ and $36.4 \%$ respectively. The liberal translation that can both reach high box office and present the connection between the original title, however, merely accounts for $28.1 \%$ in Chinese films, the lowest of the three strategies. In contrast, the application of a liberal translating strategy for English films is $37.7 \%$, the highest among the three strategies, which is a true reflection of the current research status of film title translation. The cause may be that the research on English film title translation started earlier than that on Chinese film title translation, and the results or papers on the former far exceed those on the latter. Therefore, more efforts are needed to make Chinese culture accessible to the world through films and to be accepted by the rest of the world.

Among the three different methods of liberal translation, the omission is preferred in terms of English film title translation, while Chinese film translation is more frequently conducted based on amplification, with Chinese film title translation at 6 and English at 31. Such amplifications make the title more vivid and more in line with the audience's aesthetic expectations. The omission in the Chinese film title translation is used in high frequency. The statistics show that the omission, the contents of which are unique in Chinese (culture, literature, etc) and more difficult to summarize in short English words, are bound to cause the lack of culture dissemination; but for the better promotion of film titles, being concise and clear plays a comparatively influential role.

For film title translation, the purpose is to convey the main message of the film to the audience in the target language, arouse the interest of the audience in the target language, and finally increase the box office. In combination with the purpose of film title translation and the characteristics of English and Chinese film titles, translators can use the methods of literal translation, liberal translation, and switch translation to give full play to the "four values" of film title translation (He, 2001). The three values, information, culture, and aesthetics are fundamental elements of commercial values, contributing to the realization of commercial values of Chinese films in English-speaking markets.

\section{Conclusion}

"Four values", namely informational value, cultural value, aesthetic value, and commercial value, give rise to the comparative study. The present study evaluates film title translation and analyzes it with evidence from the successful experience of E-C and C-E film title translation, comparatively discussing how the "four values" are reflected (section 3) as well as providing suggestions for C-E film title translation using proper translating techniques, respectively literal translation, liberal translation and switch translation (section 4), thus promoting the value of the film title. Realizing "four values" means that the translator should select proper translating techniques, and more often than not, employ multiple methods ( $\mathrm{Ji}, 2008)$ to present the translation in a more pleasant way.

The significance of the present study is to provide references for translators to do film title translation from Chinese to English in foreign countries. In general, the film is an art harmoniously integrated with cultural and commercial elements (Fan, 2018). As its characteristics have to be presented to the audience with the title, the function of film titles requires that a film title should not only cover linguistic and communicative transmission, but also get the promotion for cultural communication, which is reflected based on "four values". A film is an influential mass media product, which means that film titles should not only draw the attention of the audience, but also enable the film to enjoy certain status and fame. Translating film titles is very challenging because it requires the hard work of the translator. Despite references from "four values", currently, problems still exist and occasionally arise in 
film title translation. Therefore, studies based on a more comprehensive scope and sufficient examples are suggested to be further explored.

\section{Acknowledgments}

The author would like to express sincere gratitude to Dr. Luo Na for her useful suggestions and insightful comments on an earlier version of this paper. All remaining infelicities are, of course, entirely attributed to the author.

\section{References}

Bao, H. (2001). Cultural Context and Language Translation. Beijing: China National Translation and Publishing Company.

Cao, P. (2007). Discussion on English Translation of Chinese Film Titles. Film Review, 70-71. https://doi:10.16583/j.cnki.52-1014/j.2007.18.010.

Catford, J. (1965). A Linguistic Theory of Translation: An Essay in Applied Linguistics. Oxford: Oxford University Press.

Chen, J. (2020). The Subversion of Identity from Princesses to Queens - A Cultural Study on Feminism in Maleficent. International Journal of Literature and Arts, 8(3), 127-133. https://doi.org/10.11648/j.ijla.20200803.14.

Classe, O. (2000). Encyclopedia of Literary Translation into English. Fitzroy Dearborn Publishers. https://doi.org/10.4324/9780203825501.

Fan, S. (2018). Features and Translation Methods of Chinese and English Film Titles: From the perspective of Functional Skopos Theory. Journal of Western Fujian Vocational and Technical College, 20(03), 100-104.

Guo, J. (2000). Contemporary American Translation Theory. Hubei: Hubei Education Press.

Hatim, B., \& Ian, M. (1990). Discourse and the Translator. London: Longman.

He, Y. (2001). Theories and Methods of Film Title Translation. Foreign Language Teaching, 1, 56-60. https://doi:CNKI:SUN:TEAC.0.2001-01-011.

Ji, S. (2008). A Comparative Study of English and Chinese Film Title Translation. Information on Science and Technology (Academic Research), 26, 131+133. https://doi:CNKI:SUN:KJXI.0.2008-26-089.

Li, Q. (2002). Subversion of "Faithfulness" in Title Translation: Current Situation and Theoretical Basis of Film Title Translation. Journal of Beijing International Studies University, 5, 41-45. https://doi:CNKI:SUN:JDEW.0.2002-05-011.

Lian, S. (2010). A Contrastive Study of English and Chinese (addenda). Beijing: Peking University Press.

Liu, Z. (1991). Ten Lectures on Literary Translation. Beijing: China Translation \& Publishing Corporation.

Lu, Y. (2015). Chinese Translation of Foreign Language Film and Television Drama Titles from the Aesthetic Perspective. Social Sciences, 30(09), 140-142. https://doi:10.16745/j.cnki.cn62-1110/c.2015.09.006.

Newmark, P. (1981). Approaches to Translation. Oxford: Pergamon Press.

Newmark, P. (1991). About Translation. Multinational Matters (Series).

Nida, E. A. \& Taber, C. R. (1974). The Theory and Practice of Translation. Leiden: Brill Academic Pub

Nida, E. A. (2004). Principles of Correspondence. Multilingual Matters (Series).

Qian, S. (2000). Film and Television Translation - The Increasingly Important Field of Translation Field. Chinese Translation, 1, 61-65. https://doi:CNKI:SUN:ZGFY.0.2000-01-014.

Qin, Y. (2015). Introduction to the Four Principles of Film Title Translation - With Evidence from Comparative Appreciation of Mainland and Hong Kong and Taiwan Films. Journal of Kaifeng Institute of Education, 35(06), 38-39. https://doi:CNKI:SUN:KFJY.0.2015-06-019.

Shen, S. (1998). On Xin Da-ya: Yan Fu Translation Theory Research. Beijing: Business Press.

Stephen, B. W. \& Kin, S. (2003). Fundamentals of Codes, Graphs, and Iterative Decoding. Dordrecht: Kluwer Academic Publishers. 
Wan, S. \& Xu, Y. (2018). A Study on the Translation of English Film Titles from the Perspective of Reception Aesthetics. English Teacher, 18(23), 17-19. https://doi:CNKI:SUN:YJJS.0.2018-23-004.

Wang, H. (2019). Comparison and Translation of English and Chinese Animated Film Titles. International Public Relations, 11, 261+263. https://doi:10.16645/j.cnki.cn11-5281/c.2019.11.200.

Wang, H. \& Kuang, F. (2008). The Combination of Skopos Theory and Commercial Effect -- The "Origin, Flow and Confluence" view of English and Chinese Film Title Translation. Journal of Xi'an International Studies University, 02, 66-69+74. https://doi:10.16362/j.cnki.cn61-1457/h.2008.02.016.

Yang, X. \& Zhang, S. (2018). A Statistical Study on Chinese Translation of Disney Animated Film Titles. English Teacher, 18(18), 75-79. https://doi:CNKI:SUN:YJJS.0.2018-18-019.

Yue, F. (2000). Assimilation Trend of Foreign Film Titles Translated by Hong Kong Translators. Journal of Beijing Film Academy, 3, 42-45. https://doi:CNKI:SUN:BDYX.0.2000-03-006.

Zangwill, N. (2008). “Aesthetic Judgment”. Stanford Encyclopedia of Philosophy.

\section{Copyrights}

Copyright for this article is retained by the author(s), with first publication rights granted to the journal.

This is an open-access article distributed under the terms and conditions of the Creative Commons Attribution license (http://creativecommons.org/licenses/by/4.0/). 